\title{
Analysis of the coated and textured ring/liner conjunction based on a thermal mixed lubrication model
}

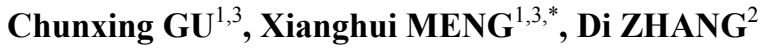 \\ ${ }^{1}$ State Key Laboratory of Mechanical System and Vibration, Shanghai Jiaotong University, Shanghai 200240, China \\ ${ }^{2}$ School of Mechanical Electronic Technology, Shanghai Jianqiao University, Shanghai 201306, China \\ ${ }^{3}$ School of Mechanical Engineering, Shanghai Jiaotong University, Shanghai 200240, China \\ Received: 21 March 2017 / Revised: 07 June 2017 / Accepted: 19 June 2017 \\ C The author(s) 2017. This article is published with open access at Springerlink.com
}

\begin{abstract}
For the ring/liner conjunction, well-designed surface texturing has been regarded as a potential means to improve its tribological performance, as well as the application of coating. However, so far most researchers focused on the one of these aspects. In this study, the combined effect of coating and texturing on the performance of ring/liner conjunction is numerically investigated. A thermal mixed lubrication model is presented. The effects of the coating's thermal and mechanical properties on the tribological performance are studied under the cold and warm engine operating conditions. Along with the increasing coating thickness, the effects of the coating's thermal properties on friction loss are found to be significant, as well as the effects of the coating's mechanical properties. It is also found that a soft coating with a lower thermal inertia has a greater ability to reduce the friction loss of the textured conjunction.
\end{abstract}

Keywords: thermal mixed lubrication; surface coating; surface texturing; piston ring; tribological performance

\section{Introduction}

In recent decades, benefits of surface texturing and coating technology are being explored by the researchers across the globe. On the one hand, surface texturing is regarded as a viable means in the reduction of the friction and wear for different tribological systems [1]. One of the evidences for this is the successful commercial application of surface texturing on the cylinder liners of combustion engines [2]. The development and effect of surface texturing in general applications have been summarized in a lot of review papers [3-7]. It is considered that the introduction of surface texturing can expand the behavior under the hydrodynamic lubrication regime instead of the mixed or boundary lubrication regimes $[5,6,8]$. On the other hand, surface coating has been used to protect contacting surfaces for a long time [9]. The coatings with the friction reduction and anti-wear properties are widely used in the different mechanical systems. In fact, the addition of coatings was first used in the case of solid-to-solid dry contacts. Over the last few decades, the use of surface coatings has also extended to the case of lubricated contacts [9-11]. It is known that a carefully selected surface coating with the appropriate mechanical and thermal properties can be used to reduce the severity of the contact.

In terms of the ring/liner conjunction, surface texturing has been regarded as a potential means to improve its tribological performance, as well as the application of coating. However, so far most researchers focused on the one of these aspects. In this study, in order to study the combined effect of the coating and texturing on the performance of ring/liner conjunction, a thermal mixed lubrication model is presented. Two kinds of texturing cases are studied, in which the textures are simulated on the ring surface and the liner surface, respectively. Benefit from the presented

* Corresponding author: Xianghui MENG, E-mail: xhmeng@sjtu.edu.cn 
model, the effects of the coating's thermal and mechanical properties on lubrication performance of the textured conjunction would be studied under the cold and warm engine operating conditions. The effect of coating's thickness would be also discussed.

\section{Model description}

In this section, the numerical model for the coated and textured contacts developed in this work is described in detail. The established model is based on the thermal mixed lubrication model introduced in the author's another article [12] for the uncoated ring/liner contacts. In brief, the corresponding numerical model for the coated and textured contacts can be split into several parts: the hydrodynamic lubrication part describing the hydrodynamic flow of the lubricant into the contact, the mechanical interaction considering the asperity contact, and the thermal part describing heat transfer between the lubricant film and the solids (contains ring, liner, and coating).

\subsection{Hydrodynamic cavitation model}

The overview of the coated and textured ring/liner conjunction is displayed in Fig. 1. As shown in Fig. 1, a layer of coating is added to the surface of ring. As for the coating, it is assumed to be bonded to the substrate (piston ring). The cross-section of the coated and textured piston ring can be considered as a slider moving over a plane supported by the oil film. It is because that the oil-film thickness is much smaller

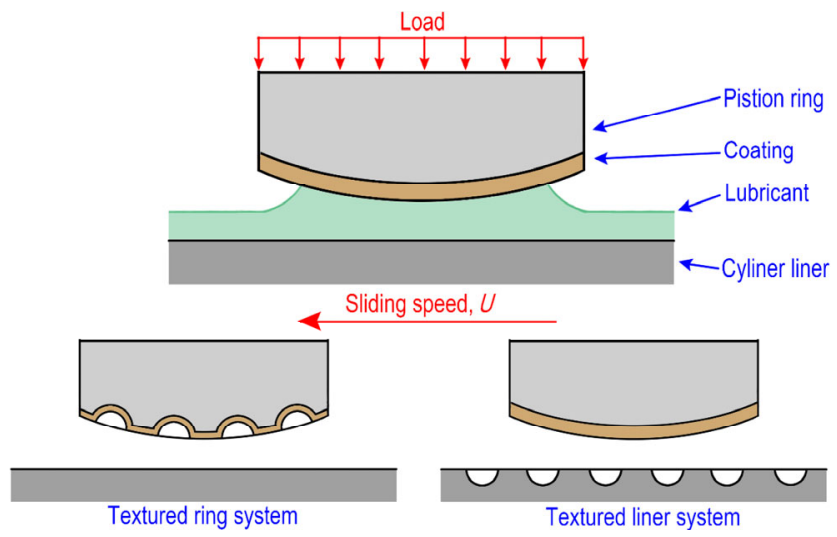

Fig. 1 The overview of the coated and textured ring/liner conjunctions, including untextured system, textured ring system, and textured liner system. than the cylinder diameter. In addition, it is noteworthy that treating the lubrication of the piston ring as a one-dimensional problem is based on the assumption that the ring is perfectly conforming in the circumferential direction.

For the ring/liner conjunction, the hydrodynamic pressures develop within the lubricant layer between the ring and liner. The source for the hydrodynamic pressure generation is the clearance. Before describing the adopted hydrodynamic cavitation model, the clearance between the ring and the liner should be well characterized. Generally, the clearance, described by oil film thickness, for the conventional ring/liner conjunction can be expressed as follows:

$$
h(x)=h_{0}+4 \frac{c x^{2}}{b^{2}}+\delta(x)
$$

where $c$ is the ring crown height, $b$ represents the ring axial width, and $h_{0}$ denotes the minimum oil film thickness. Moreover, $\delta(x)$ is the deflection induced by elastic deformation of the substrate. The calculation of $\delta(x)$ can be obtained according to the previous works $[13,14]$.

When the piston ring (coated or uncoated) is textured, the corresponding expression is changed as:

$$
\begin{aligned}
h_{\mathrm{R}}(x)= & h_{0}+4 \delta x^{2} / b^{2}+0.5 h_{\mathrm{p}}\left(\cos \left(x^{\prime} \pi / r_{\mathrm{p}}\right)+1\right) \\
& +\delta(x) \quad x \in \Omega
\end{aligned}
$$

where $h_{\mathrm{p}}$ represents the texture depth, $r_{\mathrm{p}}$ is the radius of texture, $\Omega$ denotes the area occupied by the textures. It is noteworthy that the terms $x$ and $x^{\prime}$ in the above equations are different in the Cartesian coordinates. The detailed description about $x$ and $x^{\prime}$ can be found in the work of Gu et al. [15].

Different from the expression for the textured ring, the film thickness of the textured liner can be described as $[1,16]$ :

$$
\begin{aligned}
h_{\mathrm{L}}(x, t)= & h_{0}+4 \delta x^{2} / b^{2}+0.5 h_{\mathrm{p}}\left(\cos \left(x^{\prime} \pi / r_{\mathrm{p}}\right)+1\right) \\
& +\delta(x) \quad x-U t \in \Omega
\end{aligned}
$$

where $U$ is the sliding speed.

Moreover, the prediction of the hydrodynamic pressure of the ring/liner conjunction can be carried out by the well-known JFO (Jacobsson-Floberg-Olsson) model $[17,18]$ coupled with a number of correction factors. According to the basic idea of the JFO model, 
it is described that the mass flow is a function of the hydrodynamic pressure $p$ and the cavity fraction $\theta$. The involved correction factors are called the flow factors and defined by Patir and Cheng [19]. The corresponding equations can be given as follows:

$$
\begin{aligned}
\frac{\partial}{\partial x}\left(\phi_{x} \frac{\rho}{\mu} h^{3} \frac{\partial p}{\partial x}\right)= & 6 U \phi_{\mathrm{c}} \frac{\partial[(1-\theta) \rho h]}{\partial x}+6 U \sigma \frac{\partial\left[(1-\theta) \rho \phi_{\mathrm{s}}\right]}{\partial x} \\
& +12 \phi_{\mathrm{c}} \frac{\partial[(1-\theta) \rho h]}{\partial t} \\
& p+\theta-\sqrt{p^{2}+\theta^{2}}=0
\end{aligned}
$$

where $\mu$ is the lubricant viscosity, $\rho$ symbolizes the lubricant density, $p$ denotes the hydrodynamic pressure, and $\theta$ represents the cavity fraction. It is noteworthy that the cavity fraction $\theta$ is related to the cavitation. The term $\theta$ is influenced by the hydrodynamic pressure $p$. If there is no cavitation then the fraction is zero $(\theta=0)$ and the pressure is greater than the cavitation pressure $\left(p>p_{\text {cav }}\right)$. When cavitation is present, the fraction is positive $(\theta>0)$ and the pressure is assumed to be equal to the cavitation pressure $\left(p=p_{\text {cav }}\right)$. A value of $p_{\text {cav }}=0$ is assumed as the cavitation pressure in this paper. Parameters $\phi_{x}, \phi_{c}$, and $\phi_{s}$ are the flow factors. These flow factors can be obtained according to the works of Patir et al. [19, 20]. $\sigma$ is the composite roughness for the ring and the liner, which can be calculated by the expression $\sigma=\sqrt{\sigma_{\mathrm{R}}{ }^{2}+\sigma_{\mathrm{L}}^{2}}$. In this expression, $\sigma_{\mathrm{R}}$ and $\sigma_{\mathrm{L}}$ are the roughness of the ring and the roughness of the liner, respectively. It should be mentioned that the application of constraint described in Eq. (5) could turn the hydrodynamic model into the unconstrained system of nonlinear algebraic equations. The involved calculation can benefit from a direct solver using the Fischer-Burmeister-Newton-Schur approach [21].

The lubricant rheology, involving its density and viscosity, influences the lubrication regimes. Based on the equation reported by Vogel [22] as well as the Roelands equation [23], the lubricant viscosity can be calculated by:

$$
\begin{aligned}
\mu= & {\left[a_{0} \exp \left(\frac{T_{1}}{T_{2}+T}\right)\right] \exp \left\{\left(\ln \left[a_{0} \exp \left(\frac{T_{1}}{T_{2}+T}\right)\right]\right.\right.} \\
& \left.+9.67)\left[\left(1+5.1 \times 10^{-9} p\right)^{b_{0}}-1\right]\right\}
\end{aligned}
$$

where $T$ is the lubricant temperature ( whose unit is $K$ ). Meanwhile, $a_{0}, T_{1}, T_{2}$, and $b_{0}$ are the corresponding correlation parameters. $b_{0}$ is usually considered to around 0.68 . In this way, the influence of pressure and temperature on lubricant viscosity can be obtained.

In the other hand, the influence of pressure and temperature on the lubricant density can be characterized as $[12,24]$ :

$$
\rho=\rho_{0}\left(1+\frac{0.6 p}{1+1.7 p}\right)\left[1-\beta_{\mathrm{T}}\left(T-T_{0}\right)\right]
$$

where $\rho_{0}$ is the lubricant density under the atmospheric pressure and the temperature of $T_{0} . \beta_{\mathrm{T}}$ is the thermal expansion coefficient. The detailed lubricant properties are given in Table 1.

\subsection{Asperity contact model}

In this work, the asperity contact force is obtained by the classic GT (Greenwood and Tripp) model [25]:

$$
p_{\text {asp }}=\frac{16 \sqrt{2} \pi}{15}(\eta \beta \sigma)^{2} \sqrt{\frac{\sigma}{\beta}} E^{\prime} \int_{\lambda}^{\infty}(z-\lambda)^{2.5} \phi^{*}(z) \mathrm{d} z
$$

where $\lambda$ is the Stribeck oil film ratio, which is the ratio of the mean film thickness $h$ to the composite roughness $\sigma ; \eta \beta \sigma$ is known as the Tabor's roughness parameter, while, $\sigma / \beta$ is a measure of a typical asperity slope [26]. $E^{\prime}$ is the composite effective elasticity modulus:

$$
\frac{1}{E^{\prime}}=\frac{1-v_{1}^{2}}{E_{1}}+\frac{1-v_{2}^{2}}{E_{2}}
$$

where $E_{1}$ and $E_{2}$ are the elastic modulus of the slider and the plane, respectively; $v_{1}$ and $v_{2}$ are the Poisson's

Table 1 Lubricant properties at different lubrication temperatures.

\begin{tabular}{lc}
\hline \multicolumn{1}{c}{ Parameters } & Values \\
\hline Lubricant density at $313.15 \mathrm{~K}\left(\mathrm{~kg} \cdot \mathrm{m}^{-3}\right)$ & 850 \\
Lubricant density at $393.15 \mathrm{~K}\left(\mathrm{~kg} \cdot \mathrm{m}^{-3}\right)$ & 806.48 \\
Lubricant viscosity at $313.15 \mathrm{~K}(\mathrm{mPa} \cdot \mathrm{s})$ & 35.13 \\
Lubricant viscosity at $393.15 \mathrm{~K}(\mathrm{mPa} \cdot \mathrm{s})$ & 7.71 \\
Thermal conductivity at $313.15 \mathrm{~K}\left(\mathrm{~W} \cdot \mathrm{m}^{-1} \cdot \mathrm{K}^{-1}\right)$ & 0.145 \\
Thermal conductivity at $393.15 \mathrm{~K}\left(\mathrm{~W} \cdot \mathrm{m}^{-1} \cdot \mathrm{K}^{-1}\right)$ & 0.225 \\
Specific heat capacity at $313.15 \mathrm{~K}\left(\mathrm{~J} \cdot \mathrm{kg}^{-1} \cdot \mathrm{K}^{-1}\right)$ & 1,968 \\
Specific heat capacity at $393.15 \mathrm{~K}\left(\mathrm{~J} \cdot \mathrm{kg}^{-1} \cdot \mathrm{K}^{-1}\right)$ & 2360 \\
Thermal expansion coefficient $\left(\mathrm{K}^{-1}\right)$ & $6.4 \times 10^{-4}$ \\
\hline
\end{tabular}


ratio of the slider and plane, respectively. $\phi^{*}(z)$ is the standardized height distribution. The asperity contact model is linked with the hydrodynamic model based on the load-sharing concept [27].

It is interesting to notice that two different regions are present in the rough textured surfaces. One is the untextured region. The texture features are not included in this region. Another is the textured region. It includes the texture features. Both the untextured region and the textured region are rough. In fact, when the textures are introduced, the roughness in the center and near the textures may be influenced. However, because the clearance (between two contact surfaces) in the textured region is usually more than four times the composite roughness $(\lambda>4)$, the roughness in the textured region would cause a limited or negligible effect on the lubricant flow. Therefore, according to the works of Patir and Cheng [19], the roughness in the textured region of the rough textured surfaces is not important. Similarly, the asperity contact happened in the textured region is also limited or negligible for the presence of the large clearance [25]. For simplification purpose, it is assumed that the involved asperities of the untextured region obey the Gaussian distribution. Meanwhile, the surface roughness of the untextured region is assumed to characterize the rough textured surface. In this study, the value of $\mathrm{Rq}$ is obtained based on the untextured region, which is used for calculating the composite roughness $\sigma$ as well as the Stribeck oil film ratio $\lambda$.

\subsection{Thermal model}

The thermal part is based on the heat transfer equation applied to the lubricant and contacting solids. Generally, by considering the viscous dissipation heating effect in the oil film and the roughness effect induced by asperity contact, the two-dimensional energy equation of lubricant oil can be expressed as [12]:

$$
\begin{aligned}
k_{\mathrm{p}} \frac{\partial^{2} T}{\partial z^{2}} & =\rho c_{\mathrm{p}}\left(u \frac{\partial T}{\partial x}+\frac{\partial T}{\partial t}\right)-\mu\left(\frac{\partial u}{\partial z}\right)^{2} \\
& -\beta_{\mathrm{T}} T\left(u \frac{\partial p}{\partial x}\right)-\frac{\kappa_{\mathrm{asp}} p_{\mathrm{asp}}|U|}{h}
\end{aligned}
$$

where $T$ is the lubricant temperature, $u$ denotes the fluid velocities. The term $z$ is the coordinates across the clearance. Parameters $k_{\mathrm{p}}, \beta_{\mathrm{T}}$, and $c_{\mathrm{p}}$ are the thermal conductivity, thermal expansivity, and specific heat of the lubricant, respectively. It is noteworthy that the last term in the right hand of Eq. (10) is used to consider the contribution of asperity contact to heat generation [28]. $\kappa_{\text {asp }}$ is the asperity friction coefficient. $p_{\text {asp }}$ represents the asperity contact pressure. In addition, the term $u$ is the fluid velocities in the $x$ directions. It can be obtained by:

$$
\rho\left(\frac{\partial u}{\partial t}+u \frac{\partial u}{\partial x}\right)=-\frac{\partial p}{\partial x}+\mu\left(\frac{\partial^{2} u}{\partial x^{2}}\right)
$$

In Eq. (10), the left-hand side represents conduction, while the terms on the right hand side represent viscous dissipation, compression heating, convection, and the contribution of asperity contact to heat generation, respectively. It should be noticed that the influence of the asperities on the thermal conduction is not considered in this paper. The limitation should be acknowledged.

In the solving of Eq. (10), the surface temperatures of the ring and the liner are particularly important. According to the work of Yang et al. [29], these surface temperatures can be obtained by the following equations from (12)-(17). Equations (12), (14), and (17) are the heat transfer equations of the ring, the coating, and the liner, respectively. Equation (13) is the heat flux continuity condition on the interface between the ring and the coating. Equation (15) is for the interface between the coating and the lubricant, while, Eq. (16) is for the interface between the lubricant and the liner. These equations are listed as follows:

$$
\begin{gathered}
k_{\mathrm{R}}\left(\frac{\partial^{2} T}{\partial z_{\mathrm{R}}^{2}}\right)=\rho_{\mathrm{R}} c_{\mathrm{R}}\left(U_{\mathrm{R}} \frac{\partial T}{\partial x}\right) \\
k_{\mathrm{R}} \frac{\partial T}{\partial z_{\mathrm{R}}}=k_{\mathrm{C}} \frac{\partial T}{\partial z_{\mathrm{C}}} \\
k_{\mathrm{C}}\left(\frac{\partial^{2} T}{\partial z_{\mathrm{C}}^{2}}\right)=\rho_{\mathrm{C}} c_{\mathrm{C}}\left(U_{\mathrm{C}} \frac{\partial T}{\partial x}\right) \\
k_{\mathrm{C}} \frac{\partial T}{\partial z_{\mathrm{C}}}=k \frac{\partial T}{\partial z} \\
k \frac{\partial T}{\partial z}=k_{\mathrm{L}} \frac{\partial T}{\partial z_{\mathrm{L}}} \\
k_{\mathrm{L}}\left(\frac{\partial^{2} T}{\partial z_{\mathrm{L}}^{2}}\right)=\rho_{\mathrm{L}} c_{\mathrm{L}}\left(U_{\mathrm{L}} \frac{\partial T}{\partial x}\right)
\end{gathered}
$$


where $U_{\mathrm{R}}$ is the velocity of the ring, $U_{\mathrm{L}}$ is the velocity of the liner. Since the coating is bonded to the ring, the velocity of the coating $U_{\mathrm{C}}$ is equal to the velocity of the ring $U_{R}$. Parameters $k_{R}, \rho_{R}$, and $c_{R}$ are the thermal conductivity, density, and specific heat for the ring, and parameters $k_{\mathrm{L}}, \rho_{\mathrm{L}}$, and $c_{\mathrm{L}}$ are the thermal conductivity, density, and specific heat for the liner. Parameters $k_{\mathrm{C}}, \rho_{\mathrm{C}}$, and $c_{\mathrm{C}}$ are the thermal conductivity, density, and specific heat for the coating. Coordinates $z_{R}, z_{C}$, and $z_{L}$ have the same direction as coordinate $z$. For the way about the dimensionless treatment of $z_{R}, z_{C}, z_{L}$, and $z$, the interested readers can refer to the work of Yang et al. [29].

In addition, the thermal boundary conditions should be adopted as follows:

$T=T_{\text {in }}$ at inflow on inlet side;

$\mathrm{d} T / \mathrm{d} x=0$ at outflow on inlet side;

$\mathrm{d} T / \mathrm{d} x=0$ at the outlet side;

$T=T_{\mathrm{L}}$ at the liner surface;

$T=T_{\mathrm{R}}$ at the ring surface.

Besides, as shown in Fig. 2, the inlet lubricant temperature, $T_{\text {in }}$, can be calculated as follows $[30,31]$ :

$$
T_{\text {in }}=\frac{T_{\mathrm{L}} U_{\mathrm{L}}+T_{\mathrm{C}} U_{\mathrm{C}}}{U_{\mathrm{L}}+U_{\mathrm{R}}}
$$

where $T_{\mathrm{L}}$ and $T_{\mathrm{C}}$ are the initial surface temperatures of the liner and coating. However, in the simulation of the coated and textured ring/liner system, the coated and textured ring is assumed to be stationary and the liner is assumed to undergo relative motion. Thus, according to Eq. (18), due to the convective thermal flux, $T_{\text {in }}$ is equal to $T_{\mathrm{L}}$ at the inlet. Therefore,

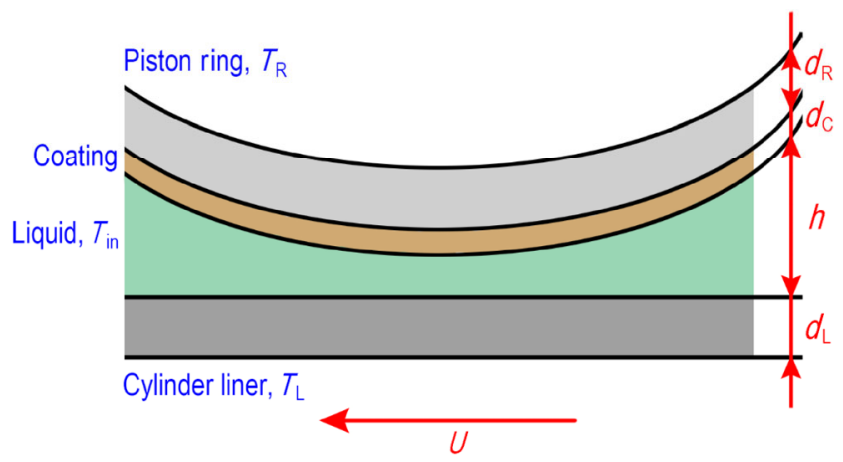

Fig. 2 Overview of the thermal analytical model for the coated and textured conjunction. in order to solve the thermal model, the liner temperature should be known a priori.

\subsection{Performance parameters}

The total friction force is evaluated as follows:

$$
\begin{gathered}
\tau=-\mu \frac{U}{h}\left(\phi_{\mathrm{f}}+\phi_{\mathrm{fs}}\right)+\phi_{\mathrm{fp}} \frac{h}{2} \frac{\partial p}{\partial x} \\
F_{\text {frc, visco }}=l_{\mathrm{r}} \int \tau(1-\theta) \mathrm{d} x \\
F_{\text {frc boun }}=\kappa_{\text {asp }} l_{\mathrm{r}} \int p_{\text {asp }} \mathrm{d} x \\
F_{\text {frc total }}=F_{\text {frc }, \text { visco }}+F_{\text {frc boun }}
\end{gathered}
$$

where $\tau$ represents the viscous shear of the lubricant. $F_{\text {frc, visco }}$ is the viscous friction. $F_{\text {frc,boun }}$ denotes the asperity contact friction. $F_{\text {fretotal }}$ symbolizes the total friction. The terms $\phi_{\mathrm{f}}, \phi_{\mathrm{fs}}$, and $\phi_{\mathrm{fp}}$ are the frictioninduced flow factors. $l_{\mathrm{r}}$ represents the circumference of the piston ring.

Moreover, the friction mean effective pressure (FMEP) parameter can be used to evaluate the engine friction loss. FMEP is the friction work normalized by engine displacement. It reads:

$$
\text { FMEP }=\frac{\int_{\text {cycle }} F_{\text {frc, total }} \mathrm{d} l_{\mathrm{s}}}{V_{\mathrm{d}}}
$$

where $V_{\mathrm{d}}$ is the engine displacement, $l_{\mathrm{s}}$ is the stroke, $\mathrm{d} l_{s}$ is the distance along the direction of the sliding stroke in each time step.

\section{Results and discussion}

In this section, a Gasoline engine at 2,000 rpm-full load is considered. Both the cold and warm engine-operating conditions are taken into account here in order to investigate the tribological benefits in terms of surface texturing and coating. In other words, the initial liner temperatures of $313.15 \mathrm{~K}$ and $393.15 \mathrm{~K}$ are adopted in the simulations, respectively. The former represents the cold engine condition while the latter is on behave of the normal operating (warm) condition. Tables 2-4 provide the necessary data for the current analysis. Among them, Table 4 shows the mechanical/thermal properties of coatings. 
Table 2 Engine data.

\begin{tabular}{cc}
\hline Parameters & Values \\
\hline Speed $(\mathrm{rpm})$ & 2,000 \\
Stroke $(\mathrm{mm})$ & 90 \\
Diameter of cylinder liner $(\mathrm{mm})$ & 84 \\
Axial width of the ring, $b(\mu \mathrm{m})$ & 1,000 \\
Height of ring crown, $c(\mu \mathrm{m})$ & 8 \\
Tension of the top ring $(\mathrm{N})$ & 20 \\
Boundary friction coefficient, $\kappa_{\text {asp }}$ & 0.12 \\
\hline
\end{tabular}

Table 3 The mechanical/thermal/surface properties for ring and liner.

\begin{tabular}{cc}
\hline Parameters & Values \\
\hline Elasticity modulus of ring, $E_{\mathrm{R}}(\mathrm{GPa})$ & 250 \\
Poisson's ratio of ring, $v_{\mathrm{R}}$ & 0.3 \\
Density of ring, $\rho_{\mathrm{R}}\left(\mathrm{kg} \cdot \mathrm{m}^{-3}\right)$ & 7,700 \\
Thermal conductivity of ring, $k_{\mathrm{R}}\left(\mathrm{W} \cdot \mathrm{m}^{-1} \cdot \mathrm{K}^{-1}\right)$ & 25 \\
Specific heat capacity of ring, $c_{\mathrm{R}}\left(\mathrm{J} \cdot \mathrm{kg}^{-1} \cdot \mathrm{K}^{-1}\right)$ & 460 \\
Rq for ring, $\sigma_{\mathrm{R}}(\mu m)$ & 0.2 \\
Elasticity modulus for liner, $E_{\mathrm{L}}(\mathrm{GPa})$ & 120 \\
Poisson's ratio for liner, $v_{L}$ & 0.3 \\
Density for liner, $\rho_{L}\left(\mathrm{~kg} \cdot \mathrm{m}^{-3}\right)$ & 7,200 \\
Thermal conductivity for liner, $k_{\mathrm{L}}\left(\mathrm{W} \cdot \mathrm{m}^{-1} \cdot \mathrm{K}^{-1}\right)$ & 55 \\
Specific heat capacity for liner, $c_{\mathrm{L}}\left(\mathrm{J} \cdot \mathrm{kg}{ }^{-1} \cdot \mathrm{K}^{-1}\right)$ & 460 \\
Rq for liner, $\sigma_{\mathrm{L}}(\mu m)$ & 0.6 \\
Roughness parameter $(\eta \beta \sigma)$ & 0.04 \\
Measure of asperity gradient $(\sigma / \beta)$ & 0.001 \\
\hline
\end{tabular}

Table 4 The mechanical/thermal properties for coatings.

\begin{tabular}{cc}
\hline Parameter & Value \\
\hline $\begin{array}{c}\text { Elasticity modulus of ring, } E_{\mathrm{C}}(\mathrm{GPa}) \\
\text { Poisson's ratio of ring, } v_{\mathrm{C}}\end{array}$ & $62.5 ; 125 ; 250 ; 500$ \\
$\begin{array}{c}\text { Density of ring, } \rho_{\mathrm{C}}\left(\mathrm{kg} \cdot \mathrm{m}^{-3}\right) \\
\text { Thermal conductivity of ring, } k_{\mathrm{C}} \\
\left(\mathrm{W} \cdot \mathrm{m}^{-1} \cdot \mathrm{K}^{-1}\right)\end{array}$ & 3,$500 ; 10,000$ \\
$\begin{array}{c}\text { Specific heat capacity of ring, } c_{\mathrm{C}} \\
\left(\mathrm{J} \cdot \mathrm{kg}^{-1} \cdot \mathrm{K}^{-1}\right)\end{array}$ & $200 ; 1,000$ \\
Coating thickness, $d_{\mathrm{C}}(\mu \mathrm{m})$ & $10 ; 20 ; 40 ; 80$ \\
\hline
\end{tabular}

In addition, the variation of piston sliding speed with the crank angle is presented in Fig. 3, as well as the cylinder pressure variation. They are used as the pivotal inputs in the related simulations. In terms of the textured systems, the adopted textures are $60 \mu \mathrm{m}$ in breadth and $3 \mu \mathrm{m}$ in height. When the piston ring is textured, four textures are evenly distributed on the ring surface. When the textured liner system is studied, the spaces (one texture per $250 \mu \mathrm{m}$ ) between every two textures are the same.

\subsection{Validation and mesh}

At first, one case is used to test the correctness and accuracy of the adopted model. The adopted simulation conditions are consistent with the published results from Bertocchi et al. [32]. The comparison results involving the hydrodynamic pressure are shown in Fig. 4. Only a difference of $0.65 \%$ in peak pressure between current model and the one presented by Bertocchi et al. [32] is detected. In other words, the result obtained by the present model matches well

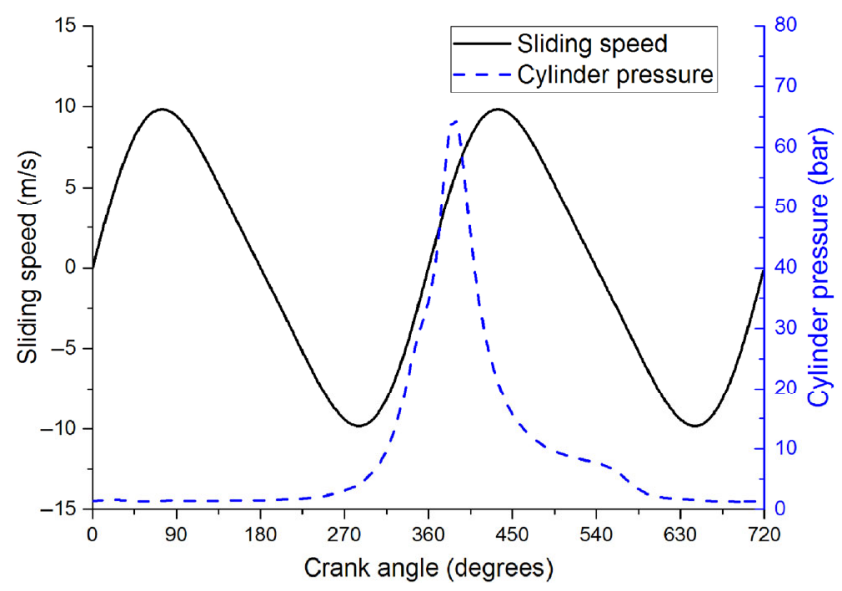

Fig. 3 The variations of sliding speed and cylinder pressure with crank angle.

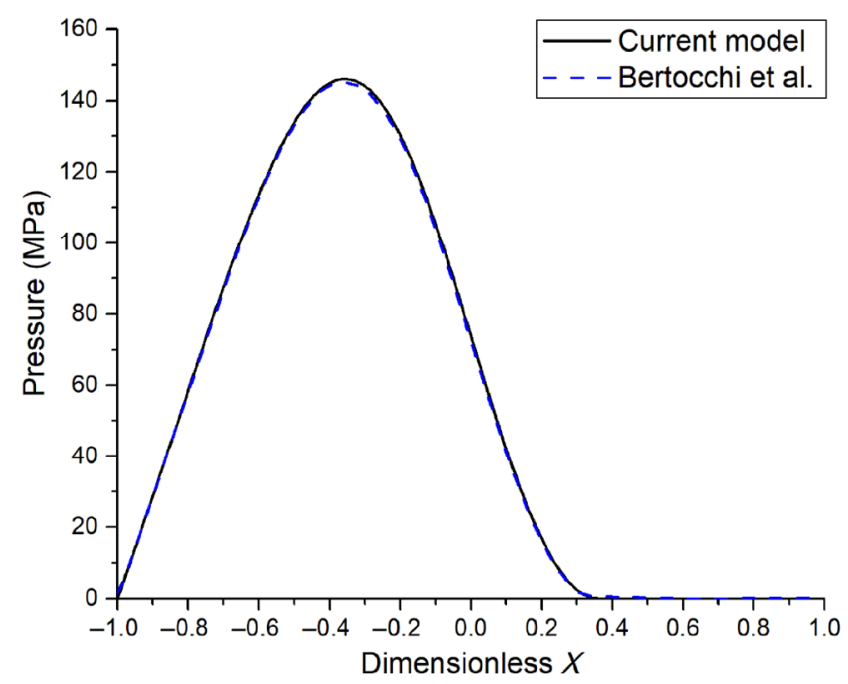

Fig. 4 The comparison results involving the hydrodynamic pressure distributions. 
with the result available in the literature.

In addition, it is noteworthy that the choice of mesh size and time step is critical for the simulation of the textured system. In the author's another paper [15], the influences of mesh size on the convergence of results have been studied, as well as the time step. It was found that the numerical errors could be ignored when 1,000 mesh and 0.05 degree per step were adopted in the simulations. Since the cases studied in this paper are similar to these given in previous paper [15], the same time step and mesh size would be adopted in this paper to keep the accuracy of the calculation.

\subsection{Effect of coating mechanical properties}

In order to isolate the effects of mechanical properties, the thermal properties of coatings are taken to be those of ring. Figure 5 shows the effect of coating's mechanical properties on the average temperature rise of lubricant when the untextured conjunction is under the cold engine condition. The coatings with different elasticity modules are employed in the corresponding simulations. Meanwhile, it should be pointed out that the average temperature rises of lubricant are the results of convention and conduction. The average viscosity value is calculated by adding the viscosity values in different nodes together and dividing by the total number of nodes. It appears that the average temperature rise for the lubricant is obvious at the middle of each stroke, but the value of average temperature rise is limited in each dead center. Moreover, as shown in Fig. 5, the average temperature rises at the power stroke are more obvious than the results at other strokes. The average temperature rise of lubricant is influenced by the applied load. In addition, according to the results from the conjunctions with different elasticity modulus of coatings, it can be found that the soft coatings can make the lubricant obtain a larger temperature rise than the hard ones. The temperature rise of lubricant may considerably alter the properties of the lubricant. As a result, different elasticity modulus of coatings would result in the various tribological performances of ring/liner conjunctions.

In order to study the performance of the coated and textured conjunction, the temperature distributions

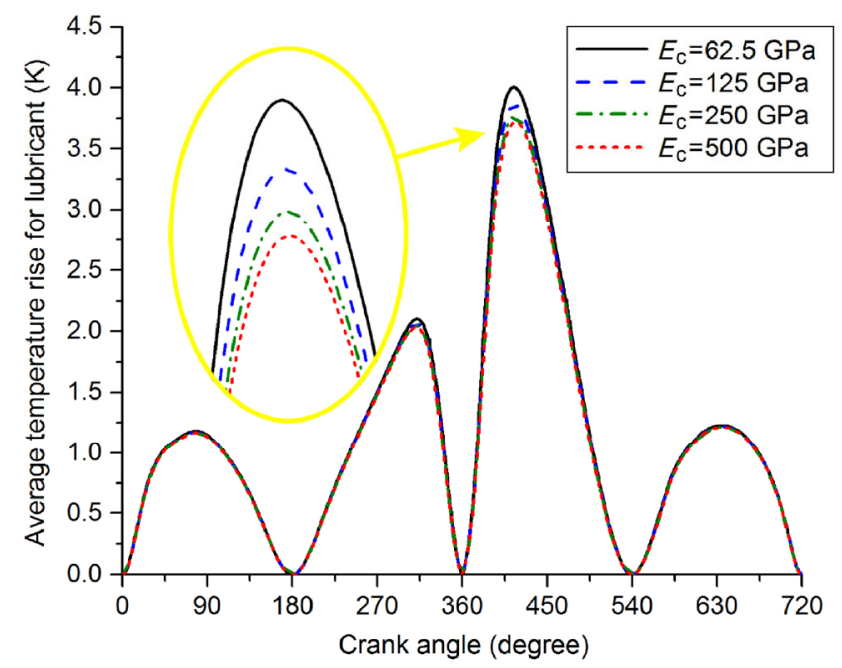

Fig. 5 The variation of average temperature rises for the lubricant when the untextured conjunctions with different elasticity modulus of coatings are under the cold engine condition.

for the untextured and textured conjunctions are displayed in Fig. 6. The crank angle is 380 degree and the bonded coating's elasticity modulus is $62.5 \mathrm{GPa}$. As shown in Fig. 6, it appears that the temperature rise mainly occurs in the middle region of the clearance. It is found that the lubricant temperature distribution for the smooth and the textured ring conjunctions are almost the same. However, it is interesting to notice that the temperature distribution for the textured liner conjunction is different from those for the smooth and the textured ring conjunctions. It should be noticed that simulating the textured liner system should always consider the effect of the transient terms. Owing to the movement of the texture features, the clearance between the untextured ring and the textured liner is changing all the time [15]. As shown in Fig. 6, the lubricant temperature peak for the textured liner conjunction is larger than these found in the smooth and the textured ring conjunctions. It seems that the viscous dissipation heating effect may be improved by the moving textures for the textured liner conjunction. The increased temperature inside the film would result in the reduced lubricant viscosity in the same region. As a result, friction would be reduced.

In order to study the effect of the coat's mechanical properties on the friction loss, the FMEP results for the untextured and textured systems under the cold engine operating condition are summarized in Fig. 7. 

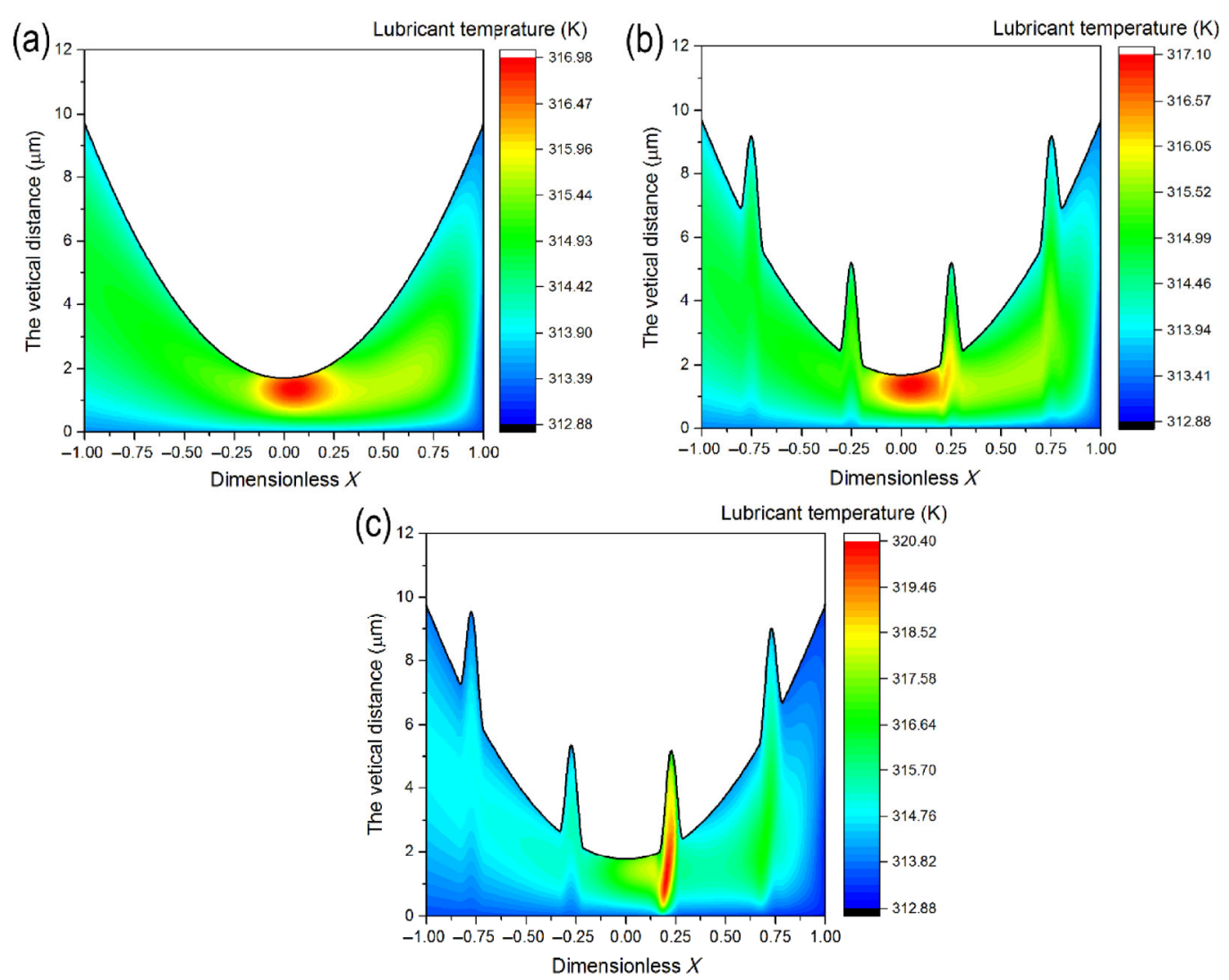

Fig. 6 The temperature distribution in oil film between the coated ring and the liner under the cold engine condition when the crank angle is 380 degree and the coating's elasticity modulus is $62.5 \mathrm{GPa}$ : (a) for the smooth conjunction; (b) for the textured ring conjunction; (c) for the textured liner conjunction.

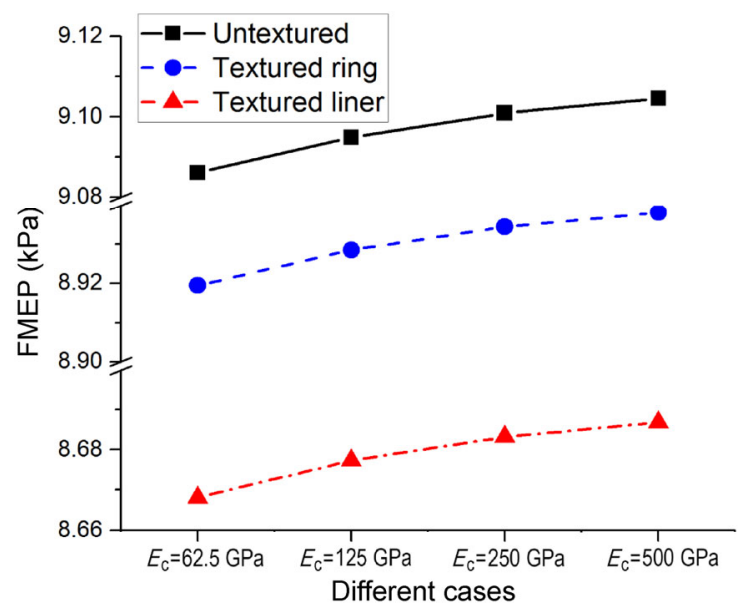

Fig. 7 The variation of FMEP results for the untextured and textured conjunctions under the cold engine condition when different Elasticity modulus of coatings are adopted.

It can be found that different elastic modulus of coatings would result in different FMEP results. The friction loss of ring/liner conjunctions can be slightly affected by the mechanical properties of coatings. For the smooth conjunction, the corresponding FMEP value is smallest when the elasticity modulus of coating is $62.5 \mathrm{GPa}$. It seems that the application of the soft coating can improve the tribological performance of ring/liner conjunction. The reason for the phenomenon that a soft coating can lead to reduced friction compared to a hard one can be explained as follows: In the mixed lubrication regime, the applied load is shared by the hydrodynamic support and asperity contact load. As mentioned in Section 2, the asperity contact load can be obtained by Eq. (8). For a soft coating, the composite effective elasticity modulus is smaller than that for a hard coating. It would lead to different asperity contact loads. In order to achieve the load balance, the oil film would be adjusted and the hydrodynamic support would be changed. Benefit from the reduced asperity contact load, the viscous friction would domain and, as a consequence, the friction loss would be reduced. Hard coatings have the exact opposite effect and lead to the increased 
friction. Furthermore, by comparing the results from the smooth conjunction with the textured conjunction results, it seems that the effect of texturing can be enhanced by the application of the soft coating. Meanwhile, when the textures are treated on the liner and the ring surface is coated with a soft coating (whose elasticity modulus is $62.5 \mathrm{GPa}$ ), it is observed that the friction loss of ring/liner conjunction can be significantly reduced. It is also found that the textured liner system has the better tribological properties than the textured ring system, when the elasticity modules of coating are the same. As reported by Gherca et al. [33], a textured moving surface can contribute to the generation of hydrodynamic lift on the basis of a squeeze effect. For more information about the difference between the stationary texturing case (or say the textured ring system) and moving texturing case (or say the textured liner system), the interested readers can refer to the works of Medina et al. [34] and Gherca et al. [33].

Figure 8 shows the simulation results under the warm engine operating condition. As shown in Fig. 8, the variations of the FMEP results for the untextured and textured conjunctions are summarized. Similar to the results under the cold engine condition presented in Fig. 7, it is also found that the friction loss under the warm engine operating condition can be reduced by using the soft coating. Obviously, the combination of soft coating and introducing the textures on the liner leads to the greatest friction decrease.

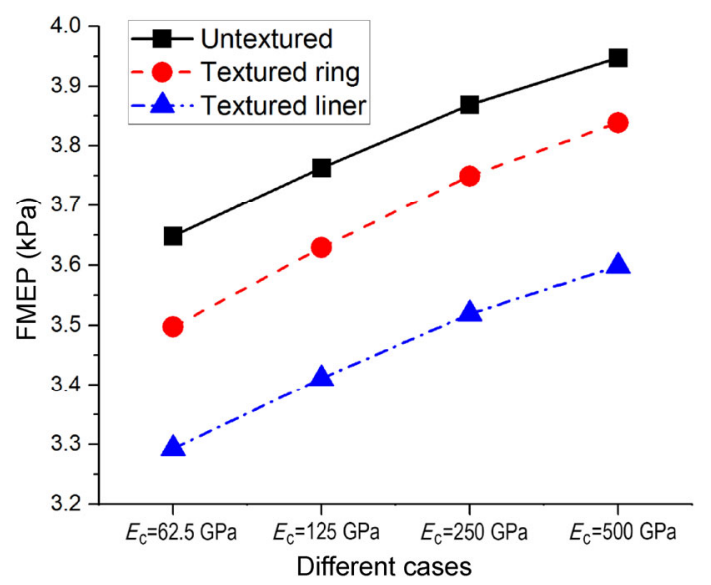

Fig. 8 The variation of FMEP results for the untextured and textured conjunctions under the warm engine condition when different elasticity modulus of coatings are adopted.
In addition, it appears that the textured liner system has the better friction reduction effect than the textured ring system, when the warm engine operating condition is considered. In fact, when textures are introduced on the liner surface, the wear of the liner would be smaller and more evenly distributed than that of ring [16]. The textures can be preserved in their shapes for a long operating time. Meanwhile, regarding the textured liner system, it allows one to optimize the texture that contacts the ring independently for each instant of the engine cycle [16].

\subsection{Effect of coating thermal properties}

In order to isolate the effects of the coating's thermal properties, the mechanical properties of the coatings are taken to be those of the ring. Two categories of coatings are considered based on their thermal inertia $I=\sqrt{k \rho c}$. Both the low $\left(\rho_{\mathrm{C}}=3,500 \mathrm{~kg} \cdot \mathrm{m}^{-3}\right.$, $\left.k_{\mathrm{C}}=5 \mathrm{~W} \cdot \mathrm{m}^{-1} \cdot \mathrm{K}^{-1}, c_{\mathrm{C}}=200 \mathrm{~J} \cdot \mathrm{kg}^{-1} \cdot \mathrm{K}^{-1}\right)$ and high $\left(\rho_{\mathrm{C}}=10,000 \mathrm{~kg} \cdot \mathrm{m}^{-3}, \quad k_{\mathrm{C}}=90 \mathrm{~W} \cdot \mathrm{m}^{-1} \cdot \mathrm{K}^{-1}, \quad c_{\mathrm{C}}=\right.$ $1,000 \mathrm{~J} \cdot \mathrm{kg}^{-1} \cdot \mathrm{K}^{-1}$ ) thermal inertia coatings are simulated, whose values are smaller than or greater than the thermal inertia of the ring, respectively. Figure 9 shows the effect of coating's thickness on the FMEP results, when the untextured ring/liner conjunctions are simulated under the cold engine operating condition. As shown in Fig. 9, it is found that the increase of the thickness for the low thermal inertia coatings leads to a more pronounced decrease in FMEP results. On the other hand, it is found that the

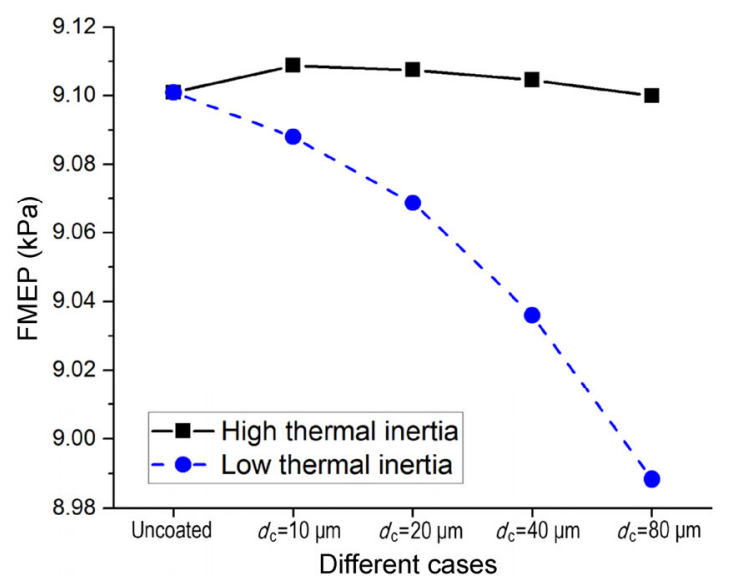

Fig. 9 The effect of coating thickness $\left(d_{c}\right)$ on FMEP results for the untextured conjunction with the high or low thermal inertia coatings. 
friction is slightly changed with the thickness of high thermal inertia coatings. Notice that the friction loss change induced by the thickness of high thermal inertia coatings is quite limited (about $0.01 \mathrm{kpa}$ ). Figure 10 shows the variations of average lubricant temperature rises when the untextured conjunctions are coated with the high or low thermal inertia coatings. For the high thermal inertia coating, the lubricant temperature rise is decreased with the increase of the coating thickness. In terms of the low thermal inertia coating, it is observed that the average temperature rise for the lubricant increases with the increasing coating thickness. As discussed in the work of Habchi [9], low thermal inertia surface coatings can act as insulators, leading to a localized increase in the lubricant's temperature. The lubricant viscosity is influenced by the lubricant temperature. The large lubricant temperature rise would lead to the low lubricant viscosity, which would result in the reduced friction.
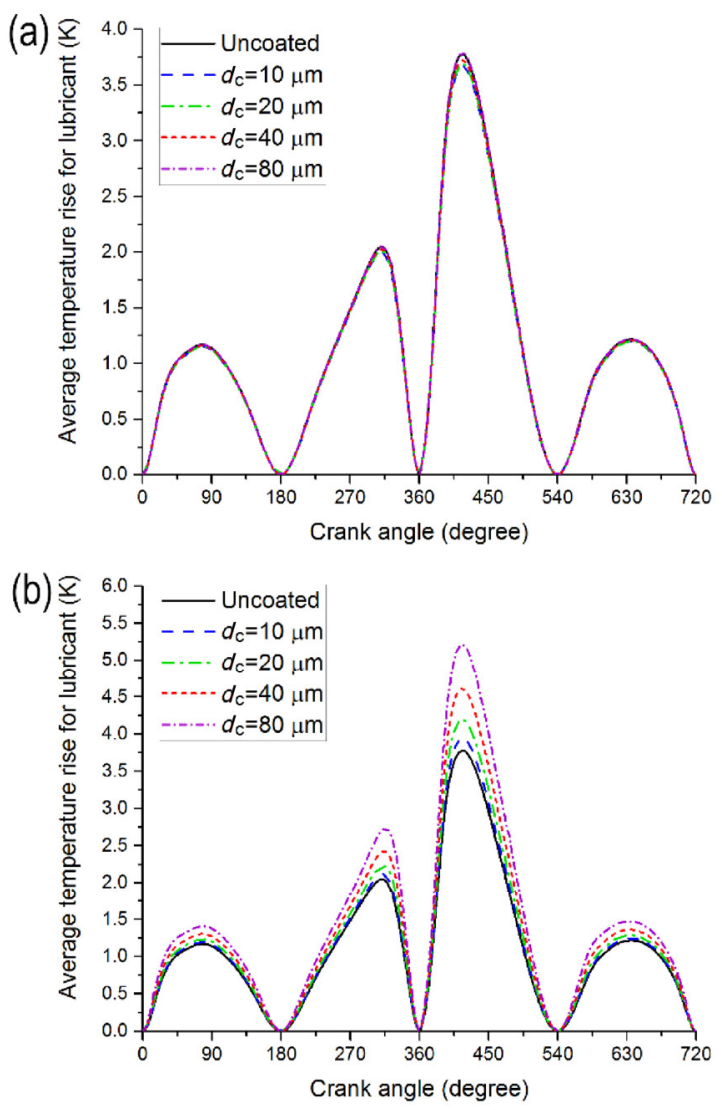

Fig. 10 The variations of average temperature rises for lubricant when different thicknesses of coatings are adopted: (a) for the high thermal inertia coating; (b) for the low thermal inertia coating.
Moreover, the FMEP results for the untextured and textured systems are summarized in Fig. 11. It is used to find the combined effect of texturing and coating on the friction loss. The adopted coating thickness is $20 \mu \mathrm{m}$. It can be found that a significant reduction of friction can be obtained when texturing is on the liner and the low thermal inertia coating is used. Obviously, the combination of the low thermal inertia coating and treating textures on the liner leads to the greatest friction decrease whereas the application of the high thermal inertia on the untextured conjunction leads to the greatest friction increase.

\section{Conclusions}

In this paper, a thermal mixed lubrication model was presented for analyzing the coated and textured ring/liner system. The combined effects of the coating and texturing under the cold and warm engine conditions were studied. The following conclusions can be drawn:

It is found that the mechanical and thermal properties of coatings would affect the tribological performance. However, it seems that the influences of coatings are relative small. Compared with the cases under the warm engine condition, the friction reduction induced by the coating is more obvious when the cold engine condition is studied.

Meanwhile, surface texturing can improve the tribological performance of ring/liner conjunction, whether under the cold or warm engine operating conditions. In particular, the effect of texturing can be

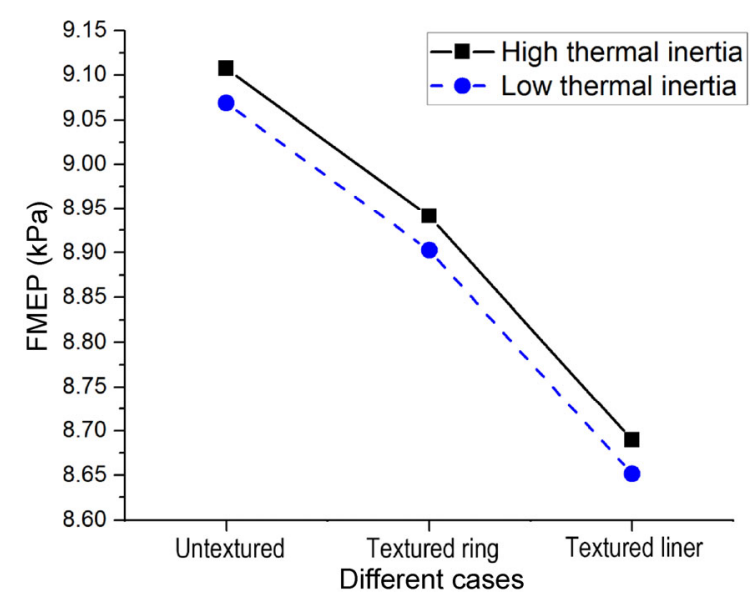

Fig. 11 The effect of coating's thermal inertia on FMEP results for the untextured or textured conjunctions. 
enhanced by the application of the soft coating with the low thermal inertia.

Besides, it is noteworthy that the application of the coating can also improve other properties, involving the surface roughness, the boundary friction coefficient, etc. However, these aspects are not considered in this study. The experimental testing would be a better alternative to study these aspects. The limitations of the approach should be acknowledged.

\section{Acknowledgements}

This study is supported by the National Natural Science Foundation of China (Nos. 51375300 and 51575342), the Research Project of State Key Laboratory of Mechanical System and Vibration (No. MSVZD201701) for supporting this research.

Open Access: The articles published in this journal are distributed under the terms of the Creative Commons Attribution 4.0 International License (http:// creativecommons.org/licenses/by/4.0/), which permits unrestricted use, distribution, and reproduction in any medium, provided you give appropriate credit to the original author(s) and the source, provide a link to the Creative Commons license, and indicate if changes were made.

\section{References}

[1] Gu C X, Meng X H, Xie Y B, Kong X L. Performance of surface texturing during start-up under starved and mixed lubrication. J Tribol 139(1): 011702 (2017)

[2] Willis E. Surface finish in relation to cylinder liners. Wear 109(1-4): 351-366 (1986)

[3] Ibatan T, Uddin M S, Chowdhury M A K. Recent development on surface texturing in enhancing tribological performance of bearing sliders. Surf Coat Technol 272: 102-120 (2015)

[4] Ahmed A, Masjuki H H, Varman M, Kalam M A, Habibullah M, Al Mahmud K A H. An overview of geometrical parameters of surface texturing for piston/cylinder assembly and mechanical seals. Meccanica 51(1): 9-23 (2016)

[5] Sudeep U, Tandon N, Pandey R K. Performance of lubricated rolling/sliding concentrated contacts with surface textures: A review. J Tribol 137(3): 031501 (2015)

[6] Gropper D, Wang L, Harvey T J. Hydrodynamic lubrication of textured surfaces: A review of modeling techniques and key findings. Tribol Int 94: 509-529 (2016)

[7] Shamsul Baharin A F, Ghazali M J, Wahab J A, Gachot C. Laser surface texturing and its contribution to friction and wear reduction: A brief review. Ind Lubricat Tribol 68(1): 57-66 (2016)

[8] Gu C X, Meng X H, Xie Y B, Zhang D. The influence of surface texturing on the transition of the lubrication regimes between a piston ring and a cylinder liner. Int J Eng Res 18(8): 785-796 (2017)

[9] Habchi W. A numerical model for the solution of thermal elastohydrodynamic lubrication in coated circular contacts. Tribol Int 73: 57-68 (2014)

[10] Habchi W, Bair S. Effect of lubricant rheology on friction in coated elastohydrodynamic lubricated contacts. Proc Inst Mech Eng Part J J Eng Tribol 231(8): 975-985 (2017)

[11] Yu C Y, Meng X H, Xie Y B. Numerical simulation of the effects of coating on thermal elastohydrodynamic lubrication in cam/tappet contact. Proc Inst Mech Eng Part J J Eng Tribol 231(2): 221-239 (2017)

[12] Gu C X, Meng X H, Xie Y B, Fan J Z. A thermal mixed lubrication model to study the textured ring/liner conjunction. Tribol Int 101: 178-193 (2016)

[13] Houpert L G, Hamrock B J. Fast approach for calculating film thicknesses and pressures in elastohydrodynamically lubricated contacts at high loads. J Tribol 108(3): 411-419 (1986)

[14] Chong W W F, Teodorescu M, Vaughan N D. Cavitation induced starvation for piston-ring/liner tribological conjunction. Tribol Int 44(4): 483-497 (2011)

[15] Gu C X, Meng X H, Xie Y B, Yang Y M. Effects of surface texturing on ring/liner friction under starved lubrication. Tribol Int 94: 591-605 (2016)

[16] Checo H M, Ausas R F, Jai M, Cadalen J P, Choukroun F, Buscaglia G C. Moving textures: Simulation of a ring sliding on a textured liner. Tribol Int 72: 131-142 (2014)

[17] Jakobsson B, Floberg L. The Finite Journal Bearing, Considering Vaporization. Göteborg (Sweden): Gumperts Förlag, 1957.

[18] Olsson K O. Cavitation in Dynamically Loaded Bearings. Göteborg (Sweden): Scandinavian University, 1965.

[19] Patir N, Cheng H S. Application of average flow model to lubrication between rough sliding surfaces. J Tribol 101(2): 220-229 (1979)

[20] Patir N, Cheng H S. An average flow model for determining effects of three-dimensional roughness on partial hydrodynamic lubrication. J Tribol 100(1): 12-17 (1978)

[21] Woloszynski T, Podsiadlo P, Stachowiak G W. Efficient solution to the cavitation problem in hydrodynamic lubrication. Tribol Lett 58: 18 (2015) 
[22] Vogel H. The law of the relation between the viscosity of liquids and the temperature. Phys Z 22: 645-646 (1921)

[23] Roelands C J A. Correlational Aspects of the ViscosityTemperature-Pressure Relationship of Lubricating Oils. TU Delft (Netherlands): Delft University of Technology, 1966.

[24] Dowson D, Higginson G R. Elasto-Hydrodynamic Lubrication: the Fundamentals of Roller and Gear Lubrication. Oxford (UK): Pergamon Press, 1966.

[25] Greenwood J A, Tripp J H. The contact of two nominally flat rough surfaces. Proc Inst Mech Eng 185(1): 625-633 (1970)

[26] Shahmohamadi H, Mohammadpour M, Rahmani R, Rahnejat H, Garner C P, Howell-Smith S. On the boundary conditions in multi-phase flow through the piston ring-cylinder liner conjunction. Tribol Int 90: 164-174 (2015)

[27] Johnson K L, Greenwood J A, Poon S Y. A simple theory of asperity contact in elastohydro-dynamic lubrication. Wear 19(1): 91-108 (1972)

[28] Masjedi M, Khonsari M M. Theoretical and experimental investigation of traction coefficient in line-contact EHL of rough surfaces. Tribol Int 70: 179-189 (2014)

[29] Yang P, Qu S, Kaneta M, Nishikawa H. Formation of steady dimples in point TEHL contacts. $J$ Tribol 123(1): 42-49 (2000)

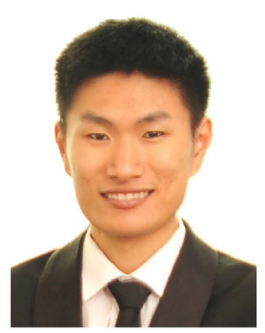

Chunxing GU. He received his bachelor and master degrees in mechanical engineering in 2011 and 2014 from Jiangsu University, Zhenjiang, China. He is studying

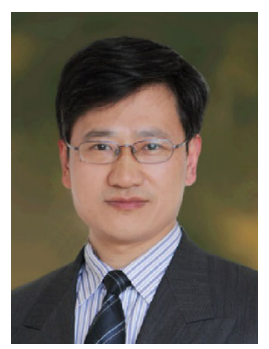

Xianghui MENG. He received his bachelor and master degrees in power machinery and Engineering from Xi'an Jiaotong University, China, in 1995 and 1999, respectively. He received his $\mathrm{PhD}$ degree in mechanical engineering from Shanghai
[30] Olver A V, Spikes H A. Prediction of traction in elastohydrodynamic lubrication. Proc Inst Mech Eng Part J J Eng Tribol 212(5): 321-332 (1998)

[31] Morris N, Rahmani R, Rahnejat H, King P D, Fitzsimons B. Tribology of piston compression ring conjunction under transient thermal mixed regime of lubrication. Tribol Int 59: 248-258 (2013)

[32] Bertocchi L, Dini D, Giacopini M, Fowell M T, Baldini A. Fluid film lubrication in the presence of cavitation: A massconserving two-dimensional formulation for compressible, piezoviscous and non-Newtonian fluids. Tribol Int 67: 61-71 (2013)

[33] Gherca A, Fatu A, Hajjam M, Maspeyrot P. Effects of surface texturing in steady-state and transient flow conditions: Two-dimensional numerical simulation using a massconserving cavitation model. Proc Inst Mech Eng Part $J \mathrm{~J}$ Eng Tribol 229(4): 505-522 (2015)

[34] Medina S, Fowell M T, Vladescu S C, Reddyhoff T, Pegg I, Olver A V, Dini D. Transient effects in lubricated textured bearings. Proc Inst Mech Eng Part J J Eng Tribol 229(4): 523-537 (2015)

for his Ph.D. degree at the Mechanical Engineering School of Shanghai Jiaotong University, Shanghai, China. His research interests include surface texturing and tribology.

Jiaotong University, China, in 2006. His current position is an associate professor and doctorial supervisor at School of Mechanical Enginnering, Shanghai Jiaotong University. His research areas cover the tribology of internal combustion engines, low friction design, and wear mechanism. 